
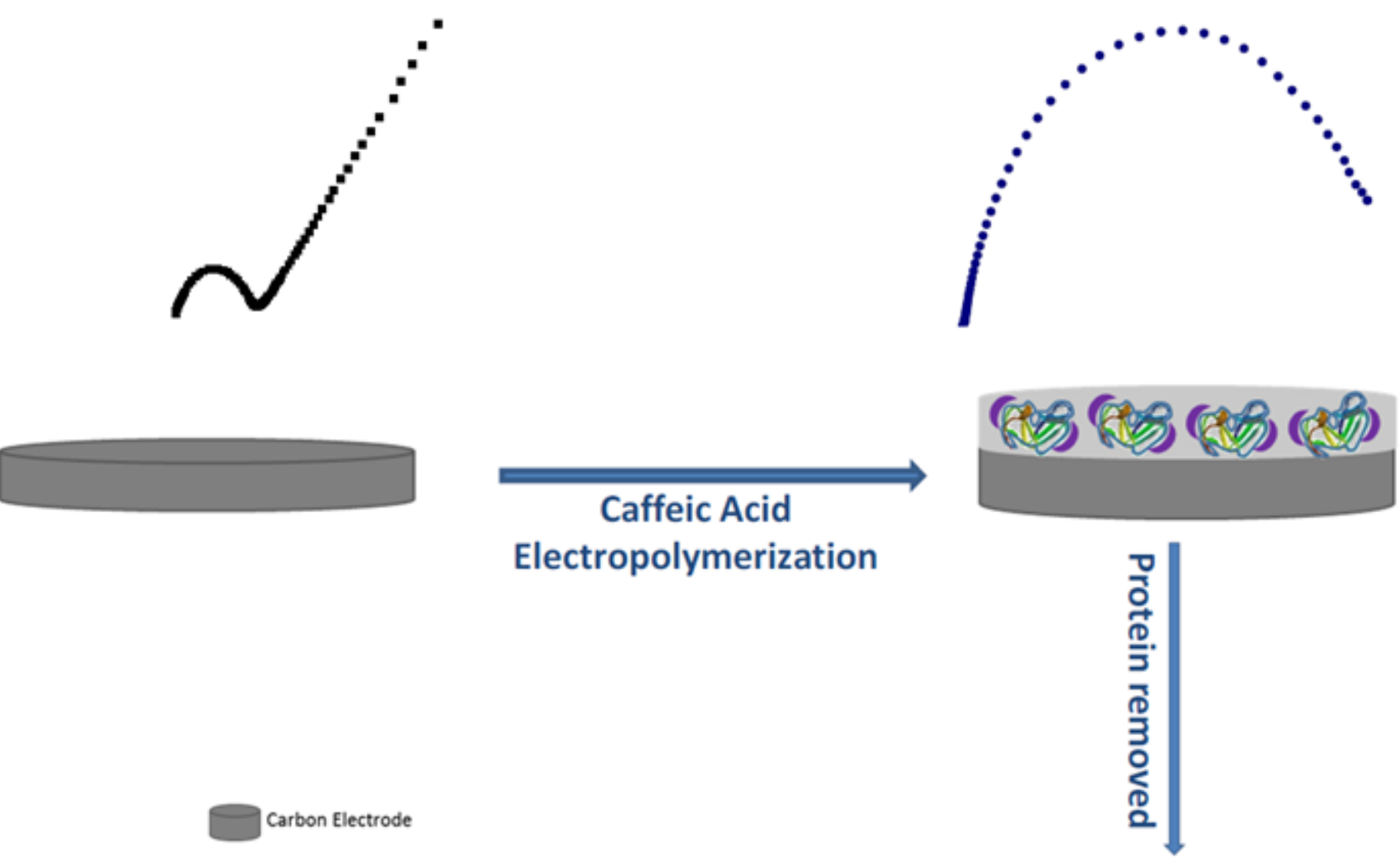

Carbon Electrode

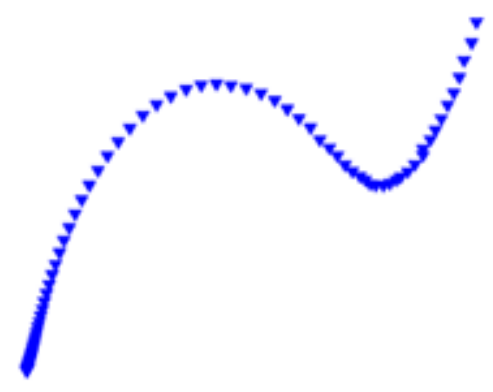

1. $\mathrm{MSMB}$

( Dopamine

\title{
Electropolymerization
}

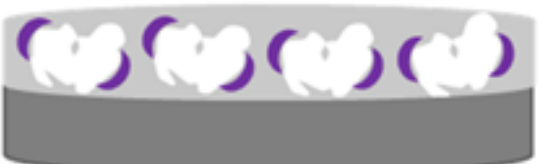




\section{Protein Imprinted Materials designed with charged binding sites on screen- printed electrode for Microseminoprotein-Beta determination in biological samples.}

Tânia S.C.R. Rebelo ${ }^{1,2,3}$, Carlos M. Pereira ${ }^{4 *}$, M. Goreti F. Sales ${ }^{1}$, J. Noronha ${ }^{2}$ and Fernando

Silva $^{4}$

${ }^{1}$ BioMark-CINTESIS/ISEP, Instituto Superior de Engenharia do Instituto Politécnico do Porto, Portugal.

${ }^{2} L A Q V$, REQUIMTE, Departamento de Química, Faculdade de Ciências e Tecnologia, Universidade Nova de Lisboa, Caparica, Portugal.

${ }^{3}$ Laboratório de Farmacologia e Biocompatibilidade Celular, Faculdade de Medicina Dentária, Universidade do Porto, Porto, Portugal.

${ }^{4}$ Centro de Investigação em Química-Linha 4, Faculdade de Ciências da Universidade do Porto, Departamento de Química e Bioquímica, Porto, Portugal.

* Corresponding author. E-mail address: cmpereir@fc.up.pt (Carlos M. Pereira). Tel: +351 220 402 641; Fax: +351220402659. 


\section{Abstract}

In the past few years a large effort is being made aiming at the development of fast and reliable tests for cancer biomarkers. Protein imprinted sensors can be a fast and reliable strategy to develop tailor made sensors for a large number of relevant molecules.

This work aims to produce, optimize and use in biological samples a biosensor for microseminoprotein-beta (MSMB).

Caffeic acid (CAF) electropolimerization was performed in the presence of MicroseminoproteinBeta (MSMB) creating target protein specific cavities on the surface of a screen-printed carbon. Dopamine was introduced as charged monomer labelling the binding site and was allowed to self-organize around the protein, the subsequent electropolimerization was made with applying a constant potential of $+2.0 \mathrm{~V}$, for $30 \mathrm{~s}$, on a carbon screen-printed electrode, immersed in a solution of protein and CAF prepared in phosphate buffer.

The sensor with charged monomers showed a more sensitive response, with an average slope of $7.59 \mu \mathrm{A} /$ decade, linear concentration range of 0.5 to $100 \mathrm{ng} / \mathrm{mL}$ and a detection limit of 0.12 $\mathrm{ng} / \mathrm{mL}$. The corresponding non-imprinted sensor displays an inconsistent response over the range of the calibration curve. The biosensor was successfully applied to the analysis of MSMB in serum and urine samples.

Keywords: Microseminoprotein-Beta, caffeic acid, electrochemical biosensor, protein imprinted materials, screen-printed electrodes, urine, serum. 


\section{Introduction}

Prostate Cancer $(\mathrm{PCa})$ is now the most common cancer in European men [1]. There are no obvious preventive strategies and, therefore, screening has been considered an important strategy to reduce the number of deaths. The motorization of the levels of the Prostate Specific Antigen (PSA) biomarker is currently recommended by medical community. However, some limitations are strongly associated with PSA detection due to false negative/positive readings. An elevated PSA level in the range $4.0-10.0 \mathrm{ng} / \mathrm{mL}$ is not always due to PCa and can be associated with other prostate conditions, including benign prostatic hyperplasia, inflammation or prostatitis, and many patients are sent to unnecessary biopsy procedures. On the other hand, PSA levels below 4.0 $\mathrm{ng} / \mathrm{mL}$ can be obtained for men with PCa [2]. Therefore, there is a need to seek for appropriate biomarkers for more accurate medical diagnosis and improve therapeutic treatments to increase long term survival rates.

MSMB and PSA are the two most abundant proteins in the secretions produced by the human prostate. MSMB is a small, nonglycosylated peptide consisting of 94 amino acids (10.7 kDa) [3], having systemic functions including growth regulation and induction of apoptosis in prostate cancer cells in vitro and in vivo [4]. In contrast with PSA, where risk of prostate cancer is related to higher PSA levels. In healthy men, MSMB levels are shown to be fairly constant independently of race and ethnicity [5]. Furthermore, MSMB levels measured in serum, urine, and prostate tissue have been shown to be statistically significantly lower in men with prostate cancer and even lower in men with aggressive disease $[6 ; 7 ; 8]$. MSMB has a high prospective as a biomarker of prostate cancer development, progression and recurrence and potentially as a target for therapeutic intervention [9]. Furthermore, the combined detection of MSMB and PSA, can be a powerful tool in diagnosing prostate cancer in a clinical setting, obviating the drawbacks of single PSA detection. 
The methods available for MSMB screening are immunoassays, such as Enzyme-Linked Immunosorbent Assay (ELISA) $[6 ; 7 ; 10 ; 11]$, immunohistochemistry methods [12;13], immunoprecipitation [14] and AutoDelfia automatic immunoassay system [5; 8] based methods. The use of an antibody as biological receptor confers a selective response for MSMB detection, although the drawbacks related to the binding irreversible nature and it's consequently nonreutilization are not yet solved. The analysis is also very expensive since it requires specific natural antibodies, which needs special handling and storage conditions. Thus, novel approaches with a simple procedure and low cost are highly needed and would be greatly appreciated.

As an alternative, a new strategy based on the use of artificial antibodies instead of the natural ones could offer higher chemical/thermal stability [15] and promote a reversible analytical response, enabling a re-use of the biosensor devices. Protein plastic antibodies are a new class of materials where proteins are imprinted within a polymer shell which is grown around the protein. For further use of the of the protein plastic antibodies the encapsulated protein is extracted afterwards. These materials are also referred as Polymer Imprinted Materials (PIM) and they can be obtained by simple surface imprinting procedures [16]. Aiming at improving the protein binding, charged monomers are added to the imprinting solution $[17,18]$. In this way charged monomers interact with the protein charged binding sites further stabilizing the protein. Upon polymerization specific binding sites are generated within the frame work of the polymer matrix improving the sensor affinity towards the imprinted protein [16]. These materials are referred in this work as Charge stabilized Polymer Imprinted Materials (C/PIM).

The PIMs based on electrochemical procedures have been widely used for the recognition and detection of template molecules $[19 ; 20 ; 21]$ and is a promising tool for the construction of simple design, high stability, rapid response and enhanced selectivity sensors devices [22]. Electrochemical polymerization is typically conducted by mixing the template and the monomer 
in solution and by applying the necessary electrical conditions to form a thin film above the electrode surface containing the template entangled in a polymeric network [23]. In this process, the monomer selection is crucial, leading to more or less conductive polymer layers [22], with different physical features.

CAF is a well-known natural phenol that can be found in seeds, fruits, tubers and herbaceous parts of many vegetable species [24]. CAF has been employed in the fabrication of electrochemical sensors for recognition and detection of some biomolecules $[25 ; 26 ; 27 ; 28 ; 29]$ offering good biocompatibility properties and simple procedures for the immobilization of biomolecules.

This work proposes a novel PIM for MSMB built on the surface of a screen-printed carbon electrode and displaying charged labels on the binding site. The construction of an electrochemical biosensor based on the electropolymerization of CAF in the presence of MSMB and dopamine was tested aiming at increasing is site specificity. Dopamine was introduced as a charged monomer able to self-organize around the protein creating, in this way, upon polymerization binding sites that will increase the specificity of the polymer imprinted material cavities towards microseminoprotein-beta. For this purpose, this work presented a systematic investigation of several analytical parameters, such as sensitivity, dynamic linear range, limit of detection and selectivity, in order to evaluate the performance of the MSMB electrochemical biosensor for the PCa screening.

\section{Experimental Procedure}

\subsection{Reagents and solutions}

Ultra-pure water (resistivity $>18 \mathrm{M} \Omega . \mathrm{cm}$ at $25^{\circ} \mathrm{C}$ ) was used throughout the work for cleaning and solution preparation. All chemicals were of analytical grade and used without any further 
purification. Caffeic acid (CAF), sodium sulfate, potassium phosphate, ammonium chloride, urea, creatinine, bovine serum albumin (BSA) and 3-hydroxytyramine (dopamine) were purchased from Sigma-Aldrich; Microseminoprotein-Beta (MSMB) from OriGene; sodium chloride from Panreac; sodium hydrogen carbonate, calcium chloride dehydrate, potassium chloride, potassium ferricyanide $\left(\mathrm{K}_{3}\left[\mathrm{Fe}(\mathrm{CN})_{6}\right]\right)$ and potassium ferrocyanide trihydrate $\left(\mathrm{K}_{4}\left[\mathrm{Fe}(\mathrm{CN})_{6}\right]\right)$ from Merck.

\subsection{Solutions}

Phosphate buffer solutions (PBS) of pH $7.2\left(0.1 \mathrm{M} \mathrm{NaH}_{2} \mathrm{PO}_{4}\right.$ and $\left.0.1 \mathrm{M} \mathrm{Na}_{2} \mathrm{HPO}_{4}\right)$ were used in this work. Stock solutions of MSMB $(\mathrm{C}=0.2 \mathrm{mg} / \mathrm{mL})$ were prepared in PBS ( $\mathrm{pH} 7.2)$ and less concentrated standards were also prepared by suitable dilution in PBS buffer solution. Electrochemical assays were performed in the presence of $5.0 \times 10^{-3} \mathrm{~mol} / \mathrm{L} \mathrm{K}_{3}\left[\mathrm{Fe}(\mathrm{CN})_{6}\right]$ and $\mathrm{K}_{4}\left[\mathrm{Fe}(\mathrm{CN})_{6}\right]$ in PBS. The synthetic urine solution used had the following composition: calcium chloride dihydrate $(1.103 \mathrm{~g} / \mathrm{L})$, sodium chloride $(2.295 \mathrm{~g} / \mathrm{L})$, sodium sulfate $(2.25 \mathrm{~g} / \mathrm{L})$, potassium phosphate $(1.40 \mathrm{~g} / \mathrm{L})$, potassium chloride $(1.60 \mathrm{~g} / \mathrm{L})$, ammonium chloride $(1.00 \mathrm{~g} / \mathrm{L})$, urea $(25.0$ $\mathrm{g} / \mathrm{L})$ and creatinine $(1.10 \mathrm{~g} / \mathrm{L})$ [30]. Artificial serum solution was prepared with the following composition: sodium chloride (7.01 g/L), sodium hydrogen carbonate (1.68 g/L) and BSA (30 $\mathrm{g} / \mathrm{L})[31]$.

\subsection{Apparatus}

The electrochemical measurements were conducted in a PGSTAT302N potentiostat/galvanostat from Metrohm Autolab, containing an impedimetric module and controlled by computer with GPES 4.9 software. Carbon screen-printed electrodes (SPEs, 4 mm diameter, DRPC110) were used as sensor platforms and were from DropSens (Spain). SPEs were connected to the Autolab by means of a suitable box, also from DropSens. 


\subsection{Procedures}

\subsubsection{Fabrication of the PIM on the carbon-SPE}

Before modification the carbon-SPE electrodes were electrochemically cleaned by cycling the potential from $-0.2 \mathrm{~V}$ to $+1.0 \mathrm{~V}$, at a $100 \mathrm{mV} / \mathrm{s}$ scan-rate, in a $0.5 \mathrm{~mol} / \mathrm{L}$ sulfuric acid solution. Cycling procedures were repeated until the resulting voltammogram are reproducible $(\sim 30$ cycles were necessary). The electrodes were then thoroughly rinsed with ultra-pure water and dried under $\mathrm{N}_{2}$ atmosphere.

Next, the imprinted layer of poly(CAF) was assembled on the cleaned carbon surface, adapting the procedure described in reference [27].

About $30 \mu \mathrm{L}$ for the preparation of PIM materials, of a solution containing $2.0 \times 10^{-4} \mathrm{~mol} / \mathrm{L}$ of CAF and $5.0 \times 10^{-3} \mathrm{mg} / \mathrm{mL}$ MSMB in PBS buffer $(\mathrm{pH} 7.2)$ were casted over the three-electrode system of the SPE. Electropolymerization was conducted by applying a constant potential of +2.0 $\mathrm{V}$ for $30 \mathrm{~s}$. The polymer modified electrode was then thoroughly washed with ultra-pure water, dried under $\mathrm{N}_{2}$ and incubated overnight in a $1 \mathrm{~mol} / \mathrm{L} \mathrm{H}_{2} \mathrm{SO}_{4}$ solution at $45^{\circ} \mathrm{C}$ in order to remove the protein [20]. The resulting PIM layer was washed with PBS buffer for several times, aiming to remove the remaining protein fragments and $\mathrm{H}_{2} \mathrm{SO}_{4}$, and finally rinsed with ultra-pure water and dried under $\mathrm{N}_{2}$.

The preparation of C/PIM was identical to PIM materials, the only difference being the addition of dopamine which was introduced as charged monomer labelling the binding site. About $30 \mu \mathrm{L}$ of a solution containing $5.0 \times 10^{-3} \mathrm{mg} / \mathrm{mL}$ of MSMB and $5.0 \times 10^{-2} \mathrm{mg} / \mathrm{mL}$ dopamine in PBS buffer (pH 7.2) was incubated overnight in fridge at $4{ }^{\circ} \mathrm{C}$. After that a solution with $2.0 \times 10^{-4} \mathrm{~mol} / \mathrm{L}$ of CAF was added.

The procedure adopted for the preparation of the PIM and C/PIM are described in Figure 1. 
As a control, the non-imprinted materials NIM and C/NIM modified carbon-SPE were subject to the same procedure, except for the absence of MSMB in the electropolymerization process.

\section{Please insert Figure 1 here}

\subsubsection{Electrochemical procedures}

SWV and EIS measurements were conducted in triplicate and a redox probe solution containing $5.0 \times 10^{-3} \mathrm{~mol} / \mathrm{L}\left[\mathrm{Fe}(\mathrm{CN})_{6}\right]^{3-}$ and $\left[\mathrm{Fe}(\mathrm{CN})_{6}\right]^{4-}$, was prepared in PBS buffer of $\mathrm{pH} 7.2$, was used. In SWV a potential window from -0.5 to $0.6 \mathrm{~V}$, was used at a frequency of $10 \mathrm{~Hz}$, a step potential of $10 \mathrm{mV}$ and amplitude of $50 \mathrm{mV}$. EIS was performed at open circuit potential $(+0.12 \mathrm{~V})$, using a sinusoidal potential perturbation with an amplitude of $0.1 \mathrm{mV}$ and the number of frequencies equal to 50 , logarithmically distributed over a frequency range of $0.1-100 \mathrm{kHz}$.

Calibration curves plot were built from peak current values obtained from SWV measurements as a function of MSMB concentration range (between 0.1 and $200 \mathrm{ng} / \mathrm{mL}$ ), in PBS buffer (pH 7.2). All experiments were carried out using a $0.1 \mathrm{M} \mathrm{PBS} \mathrm{pH} \mathrm{7.2,} \mathrm{an} \mathrm{electrolyte} \mathrm{solution} \mathrm{close} \mathrm{to} \mathrm{the}$ physiological conditions.

\subsubsection{Determination of MSMB in synthetic urine and artificial serum}

Synthetic urine and artificial serum solutions with different concentrations of MSMB were used

for the evaluation of sensor response. They were prepared by adding a known amount of MSMB (from 0.2 to $20.0 \mathrm{ng} / \mathrm{mL}$ ) to the synthetic urine or to the artificial serum solution.

\section{Results and discussions}

\subsection{Imprinting stage}


From previous studies (results not shown) the polymerization of CAF is favored by applying a voltage of +2.0 our previous experience demonstrated that applying a potential pulse for $30 \mathrm{~s}$, with fixed concentration of $2.0 \times 10^{-4} \mathrm{~mol} / \mathrm{L}$ of CAF and the MSMB concentration used in the PIM construction is $5 \times 10^{-3} \mathrm{ng} / \mathrm{mL}$.

Charge/polar labels were introduced (C) to the binding site of the imprinted material (C/PIM), during the imprinting stage. This was done by adding to the solution protonated dopamine with a positive charge. Dopamine was present in a higher molar amount due to the negative overall net charge of MSMB (isoelectric point of 5.6) under physiological conditions.

The imprinted sites were obtained by removing the protein template with $1 \mathrm{~mol} / \mathrm{L} \mathrm{H}_{2} \mathrm{SO}_{4}$ solution at $45^{\circ} \mathrm{C}$ incubated overnight.

\subsection{Control of the surface modification by impedance measurement}

EIS studies were used to follow the carbon-SPE modification after each chemical change. These can be probed by monitoring the changes in the electron transfer properties of redox systems, such as $\left[\mathrm{Fe}(\mathrm{CN})_{6}\right]^{4-} /\left[\mathrm{Fe}(\mathrm{CN})_{6}\right]^{3-}$, as shown in Fig.2. Data was fitted to the Randles equivalent circuit in order to extract the numerical values of the charge transfer resistance and the values obtained are displayed in Table 1. The diameter of the semicircle in the Nyquist plot corresponds to a pseudo charge-transfer resistance (Rct) of the redox probe at electrode/electrolyte interface.

Results obtained clearly show an increase in the resistance of charge transfer after polymerization due to the barrier effect of the polymer matrix decreasing the redox probe ability to access the electrode surface. This increase is visible both for PIM and C/PIM, due to the modifications made on the electrode surface which interfere (making the access to the surface more difficult) in the charge transfer process $\left(\left[\mathrm{Fe}(\mathrm{CN})_{6}\right]^{4-} /\left[\mathrm{Fe}(\mathrm{CN})_{6}\right]^{3-}\right)$ at the electrode surface. It is noteworthy that the increase in charge transfer resistance is greater in the case of C/PIM, were the polymerization 
was performed in presence of dopamine. This cannot, obviously, be related to an eletctrostatic effect but it is most probably due to the modification of the pathways within the polymer matrix affecting the redox probe ability to access the electrode surface.

In the final step of the PIM and C/PIM synthesis, after the protein removal with $\mathrm{H}_{2} \mathrm{SO}_{4}$, a decrease in the charge transfer resistance was observed, suggesting that MSMB was successfully extracted from the polymer.

In the same way, an increase in the charge transfer resistance was observed for the NIM and C/NIM electrode after the eletropolymerization of CAF in absence of MSMB. After, the treatment of the electrode surface with $\mathrm{H}_{2} \mathrm{SO}_{4}$, the EIS profiles obtained were similar to the PIM and C/PIM electrodes, indicating the removal of a small fraction of polymer attached to the electrode surface.

\section{Please insert Figure 2 here}

\section{Please insert Table 1 here}

\subsection{Performance of the sensors}

MSMB sensors were prepared without and with charged labels (PIM or C/PIM). The main analytical features of the devices were evaluated by SWV. This technique offers, as advantage, high sensitivity to surface-confined electrode reactions, along with suitable detection capabilities and rapidity.

The calibrations curves obtained are shown in Fig. 3 and plot peak current as function of MSMB logarithm concentration (between 0.050 and $200 \mathrm{ng} / \mathrm{mL}$ ). MSMB binding was revealed by a decrease in the typical anodic peak current of the $\left[\mathrm{Fe}(\mathrm{CN})_{6}\right]^{4-} /\left[\mathrm{Fe}(\mathrm{CN})_{6}\right]^{3-}$ redox probe. Higher MSMB concentrations yielded smaller current peaks. Observing Fig. 3 it is found that the 
calibration curves for PIM and C/PIM follow a linear pattern versus log[MSMB] respectively in a concentrations range from 0.1 to $200 \mathrm{ng} / \mathrm{mL}$ and 0.5 to $100 \mathrm{ng} / \mathrm{mL}$ and a correlation coefficient of 0.9939 and 0.9945 . The limit of detection (LOD) was $0.090 \mathrm{ng} / \mathrm{mL}$ for PIM and $0.12 \mathrm{ng} / \mathrm{mL}$ for C/PIM which were estimated by the intersection of the two linear parts of the response function [32]. Analyzing the calibration curves we suggest that the best sensor would be PIM, because it has a larger working range and greater LOD, although it has lower sensitivity than the C/MIP sensor with slopes of -6.67 and $-7.59 \mu \mathrm{A} /$ decade $[\mathrm{MSMB}, \mathrm{ng} / \mathrm{mL}]$, respectively.

The NIM and C/NIM sensors feature an inconsistent response over the range of the calibration curves, (Fig.3). These results indicated that in this case the interaction between the protein and polymer was random and uncontrolled.

\section{Please insert Figure 3 here}

\subsection{Interference study and electrode stability}

The selectivity of the sensor is very important for a successful analytical application. The biosensors studied here have been exposed to many interferences that are present in biological fluids, when in contact with synthetic urine and serum, and showed a good analytical performance. Therefore, in the present study, instead of studying the individual effect of each interfering species a global approach was adopted studying the effect of using the biological fluid containing the most usual interfering species accounting, in this way to possible synergetic effects.

The interferences study was carried out by comparing the linear ranges, slopes and the LODs obtained through the concentration curves of PIM and C/PIM sensors in serum and artificial urine, the results were resumed in Table 2. The results obtained shown that PIM sensor in contact 
with biological fluids decreases its sensitivity (-5.50 $\mu \mathrm{A} /$ decade serum; $-6.38 \mu \mathrm{A} /$ decade urine), LODs $(0.10 \mathrm{ng} / \mathrm{mL}$ serum; $0.18 \mathrm{ng} / \mathrm{mL}$ urine) and linear concentration range $(0.5-200 \mathrm{ng} / \mathrm{mL})$, while the C/PIM sensor increased sensitivity (-7.95 $\mu \mathrm{A} /$ decade serum; $-13.52 \mu \mathrm{A} /$ decade urine), LODs $(0.084 \mathrm{ng} / \mathrm{mL}$ serum; $0.079 \mathrm{ng} / \mathrm{mL}$ urine $)$ and kept the linear concentration range $(0.5-100$ $\mathrm{ng} / \mathrm{mL}$ ). Once average values of MSMB present in the serum are around $12 \mathrm{ng} / \mathrm{mL}$ and, in the worst case scenario, the present sensor is capable to measure concentrations of MSMB from 0.5 $\mathrm{ng} / \mathrm{mL}$ it will be able to detect the decrease in MSMB concentrations due to prostate cancer related processes [5].

The biosensor offers a stable response within time and could be re-used a few times ( $\approx 3$ times). Reusing was possible after cleaning with $1 \mathrm{~mol} / \mathrm{L} \mathrm{H}_{2} \mathrm{SO}_{4}$ for $12 \mathrm{~h}$ at $45{ }^{\circ} \mathrm{C}$ and subsequent washing with PBS and ultra-pure water. The graphs in figure 4 display the calibration plots for the reuse of different sensors. As observed by the third time the sensor is used a loss of linearity of the sensor response is evident showing the limitation of the biosensor reuse. However this limitation is due to the physical degradation of the carbon SPE biosensor rather than a problem solely attributed to the degradation of the polymeric matrix. This is probably due to the repeated effect of the $1 \mathrm{~mol} / \mathrm{L} \mathrm{H}_{2} \mathrm{SO}_{4}$ solution at $45^{\circ} \mathrm{C}$ causing the degradation of the carbon ink and of the polymer matrix.

In these conditions, the biosensor response has an average relative standard deviation of 5\%.

As discussed previously in PBS, PIM shown better characteristics however when biosensors were studied in biological fluids C/PIM improves significantly sensibility (slope) and LOD.

Due to the mentioned above, C/PIM is the chosen biosensor to proceed with this study, although the decrease of linear concentration range in upper limits (which as no importance to our purpose once $12 \mathrm{ng} / \mathrm{mL}$ is the upper limit in real cases). 


\section{Please insert table 2 here}

\section{Please insert Figure 4 here}

\subsection{Application}

The C/PIM biosensor was used for the determination of MSMB in artificial urine and serum samples. Blank samples of synthetic urine and serum were spiked with MSMB in order to obtain concentrations ranging from 0.2 to $20.0 \mathrm{ng} / \mathrm{mL}$. The results obtained for the four concentration values are summarized in Table 3 .

For samples 2, 3 and 4 in serum, the recoveries ranged from 92.8 to $104.1 \%$ with an average relative error of $4.9 \%$, in urine the recoveries ranged from 91.5 to $104.9 \%$ with an average relative error of $5.7 \%$, these results suggesting that the proposed sensor may have success in real applications. Sample 1, in serum and urine, has weak recoveries and high relative errors, this is due to be working out of the linear range of the biosensor although it is within the LOD.

\section{Conclusions}

Molecular imprinting process over the surface of a carbon-SPE produces a simple and low cost electrochemical sensor for the determination of MSMB in biological fluids. The presence of charged labels in the imprinting phase enables the synthesis of a more sensitive device. The chosen biosensor was obtained by electropolymerization of CAF in the presence of MSMB and dopamine on carbon electrode.

In general, the C/PIM biosensor showed simplicity in design, short measuring time, reusability, low limit of detection and good selectivity. This biosensor was successfully applied to the 
analysis of MSMB in serum and urine artificial samples. For future developments it is important to proceed with clinical trials and to establish a correlation between MSMB and PSA levels.

The performance of the electrochemical biosensor presented in this work enable us to conclude that, in a near future, this can be a valuable alternative method for screening MSMB in point-ofcare.

\section{Acknowledgements}

This work was supported by FCT, Foundation for Science and Technology through the PhD grant ref. SFRH/BD/79221/2011 and CIQUP (Pest-C/QUI/U10081/2013).

\section{References}

[1] J. Ferlay, E. Steliarova-Foucher, J. Lortet-Tieulent, S. Rosso, J.W.W. Coebergh, H. Comber, D. Forman, and F. Bray, Cancer incidence and mortality patterns in Europe: Estimates for 40 countries in 2012. European Journal of Cancer 49 (2013) 1374-1403.

[2] E.S. Leman, and R.H. Getzenberg, Biomarkers for prostate cancer. Journal of Cellular Biochemistry 108 (2009) 3-9.

[3] D. Wu, Y. Guo, A.F. Chambers, J.I. Izawa, J.L. Chin, and J.W. Xuan, Serum bound forms of PSP94 (prostate secretory protein of 94 amino acids) in prostate cancer patients, J Cell Biochem, 1999 Wiley-Liss, Inc., United States, 1999, pp. 71-83.

[4] S.V. Garde, V.S. Basrur, L. Li, M.A. Finkelman, A. Krishan, L. Wellham, E. Ben-Josef, M. Haddad, J.D. Taylor, A.T. Porter, and D.G. Tang, Prostate secretory protein (PSP94) suppresses the growth of androgen-independent prostate cancer cell line (PC3) and xenografts by inducing apoptosis. The Prostate 38 (1999) 118-125.

[5] C. Valtonen-André, C. Sävblom, P. Fernlund, H. Lilja, A. Giwercman, and Å. Lundwall, Beta-Microseminoprotein in Serum Correlates With the Levels in Seminal Plasma of Young, Healthy Males. Journal of Andrology 29 (2008) 330-337.

[6] R.K. Nam, J.R. Reeves, A. Toi, H. Dulude, J. Trachtenberg, M. Emami, L. Daigneault, C. Panchal, L. Sugar, M.A.S. Jewett, and S.A. Narod, A Novel Serum Marker, Total Prostate Secretory Protein of 94 Amino Acids, Improves Prostate Cancer Detection and Helps Identify High Grade Cancers at Diagnosis. The Journal of Urology 175 (2006) 1291-1297.

[7] H.C. Whitaker, Z. Kote-Jarai, H. Ross-Adams, A.Y. Warren, J. Burge, A. George, E. Bancroft, S. Jhavar, D. Leongamornlert, M. Tymrakiewicz, E. Saunders, E. Page, A. Mitra, G. Mitchell, G.J. Lindeman, D.G. Evans, I. Blanco, C. Mercer, W.S. Rubinstein, V. Clowes, F. Douglas, S. Hodgson, L. Walker, A. Donaldson, L. Izatt, H. Dorkins, A. Male, K. Tucker, A. Stapleton, J. Lam, J. Kirk, H. Lilja, D. Easton, C. Cooper, R. Eeles, D.E. Neal, I.S.S.C. The, I.S.C. The, and U.G. Collaborators, The rs10993994 Risk Allele for Prostate Cancer Results in 
Clinically Relevant Changes in Microseminoprotein-Beta Expression in Tissue and Urine. PLoS ONE 5 (2010) e13363.

[8] C.A. Haiman, D.O. Stram, A.J. Vickers, L.R. Wilkens, K. Braun, C. Valtonen-André, M. Peltola, K. Pettersson, K.M. Waters, L.L. Marchand, L.N. Kolonel, B.E. Henderson, and H. Lilja, Levels of Beta-Microseminoprotein in Blood and Risk of Prostate Cancer in Multiple Populations. Journal of the National Cancer Institute 105 (2013) 237-243.

[9] H.C. Whitaker, A.Y. Warren, R. Eeles, Z. Kote-Jarai, and D.E. Neal, The potential value of microseminoprotein- $\beta$ as a prostate cancer biomarker and therapeutic target. The Prostate 70 (2010) 333-340.

[10] N. Anahí Franchi, C. Avendaño, R.I. Molina, A.D. Tissera, C.A. Maldonado, S. Oehninger, and C.E. Coronel, $\beta$-Microseminoprotein in human spermatozoa and its potential role in male fertility. Reproduction 136 (2008) 157-166.

[11] J.R. Reeves, H. Dulude, C. Panchal, L. Daigneault, and D.M. Ramnani, Prognostic Value of Prostate Secretory Protein of 94 Amino Acids and its Binding Protein after Radical

Prostatectomy. Clinical Cancer Research 12 (2006) 6018-6022.

[12] A. Dahlman, E. Rexhepaj, D.J. Brennan, W.M. Gallagher, A. Gaber, A. Lindgren, K. Jirstrom, and A. Bjartell, Evaluation of the prognostic significance of MSMB and CRISP3 in prostate cancer using automated image analysis. Mod Pathol 24 (2011) 708-719.

[13] Y. Imasato, J.W. Xuan, H. Sakai, J.I. Izawa, Y. Saito, J.L. Chin, and M. Moussa, PSP94 expression after androgen deprivation therapy: a comparative study with prostate specific antigen in benign prostate and prostate cancer. The Journal of Urology 164 (2000) 1819-1824.

[14] J.-P. Yang, M.A. Finkelman, and M.W. Clarke, Detection of psp94 and its specific binding sites in the prostate adenocarcinoma cell line lncap. The Journal of Urology 160 2240-2244.

[15] K.H.a.K. Mosbach, Molecularly Imprinted Polymers and Their Use in Biomimetic Sensors. Chemical Reviews 100 (2000) 2495-2504.

[16] F.T.C. Moreira, R.A.F. Dutra, J.P.C. Noronha, and M.G.F. Sales1, Surface Imprinting approach on screen printed electrodes coated with carboxylated PVC for Myoglobin detection with Electrochemical Transduction Procedia Engineering 47 (2012) 865-868.

[17] S.S. FTC Moreira, RAF Dutra, JPC Noronha, AEG Cass, MGF Sales, Smart Plastic Antibody Material (SPAM) tailored on disposable screen printed electrodes for protein recognition: application to Myoglobin detection. Biosensors and Bioelectronics 45 (2013) 237244.

[18] T.S.C.R. Rebelo, C. Santos, J. Costa-Rodrigues, M.H. Fernandes, J.P. Noronha, and M.G.F. Sales, Novel Prostate Specific Antigen plastic antibody designed with charged binding sites for an improved protein binding and its application in a biosensor of potentiometric transduction. Electrochimica Acta 132 (2014) 142-150.

[19] A. Ramanaviciene, and A. Ramanavicius, Molecularly imprinted polypyrrole-based synthetic receptor for direct detection of bovine leukemia virus glycoproteins. Biosens Bioelectron 20 (2004) 1076-82.

[20] X. Kan, Z. Xing, A. Zhu, Z. Zhao, G. Xu, C. Li, and H. Zhou, Molecularly imprinted polymers based electrochemical sensor for bovine hemoglobin recognition. Sensors and Actuators B: Chemical 168 (2012) 395-401.

[21] M.R. Subrayal, S. Giulia, and P. Quan, Electrochemical probing of selective haemoglobin binding in hydrogel-based molecularly imprinted polymers. Electrochim Acta 56 (2011) 92039208.

[22] X. Qin, H. Xiao-Ya, and H. Shi-Rong, Electrochemical sensors based on electropolymerized films. in: E. Schab-Balcerzak, (Ed.), Electropolymerization, 2011, pp. 226. 
[23] F.T.C. Moreira, S. Sharma, R.A.F. Dutra, J.P.C. Noronha, A.E.G. Cass, and M.G.F. Sales, Protein-responsive polymers for point-of-care detection of cardiac biomarker. Sensors and Actuators B: Chemical 196 (2014) 123-132.

[24] M. Nardini, P. Pisu, V. Gentili, F. Natella, M. Di Felice, E. Piccolella, and C. Scaccini, Effect of caffeic acid on tert-butyl hydroperoxide-induced oxidative stress in U937. Free Radic Biol Med 25 (1998) 1098-105.

[25] H. Filik, A.A. Avan, S. Aydar, and G. Çetintaş, Determination of Acetaminophen in the Presence of Ascorbic Acid Using a Glassy Carbon Electrode Modified with Poly(Caffeic acid). International Journal of Electrochemical Science 9 (2014) 148-160.

[26] W. Ren, H.Q. Luo, and N.B. Li, Simultaneous voltammetric measurement of ascorbic acid, epinephrine and uric acid at a glassy carbon electrode modified with caffeic acid. Biosensors and Bioelectronics 21 (2006) 1086-1092.

[27] W. Ren, H.Q. Luo, and N.B. Li, Electrochemical Behavior of Epinephrine at a Glassy Carbon Electrode Modified by Electrodeposited Films of Caffeic Acid. Sensors (Basel, Switzerland) 6 (2006) 80-89.

[28] N.B. Li, W. Ren, and H.Q. Luo, Caffeic Acid-Modified Glassy Carbon Electrode for the Simultaneous Determination of Epinephrine and Dopamine. Electroanalysis 19 (2007) 14961502.

[29] P. T. Lee, K. R. Ward, K. Tschulik, G. Chapman, and R.G. Compton, Electrochemical Detection of Glutathione Using a Poly(caffeic acid) Nanocarbon Composite Modified Electrode. Electroanalysis 26 (2014) 366-373.

[30] C.J. Collins, A. Berduque, and D.W.M. Arrigan, Electrochemically Modulated Liquid-Liquid Extraction of Ionized Drugs under Physiological Conditions. Analytical Chemistry 80 (2008) 8102-8108.

[31] K.P.G. Ralloff, P. Westh, R.A. Purssell, M. Pudek, and Y. Koga, Non-ideality of methanol solution's of artificial serum in the mole fraction range from $5 \times 10(-4)$ to $5 \times 10(-3)$ at 25 degrees C. Fluid phase equilibria 207 (2003) 301-317.

[32] R.P. Buck, and E. Lindner, Recommendations for nomenclature of ion-selective electrodes (IUPAC Recommendations 1994). Pure and Applied Chemistry 66 (1994) 2527-2536. 
Protein Imprinted Materials designed with charged binding sites on screen-printed electrode for Microseminoprotein-Beta determination in biological samples.

Tânia S.C.R. Rebelo ${ }^{1,2,3}$, Carlos M. Pereira**, M. Goreti F. Sales ${ }^{1}$, João P. Noronha ${ }^{2}$ and Fernando Silva ${ }^{4}$

${ }^{1}$ BioMark-CINTESIS/ISEP, Instituto Superior de Engenharia do Instituto Politécnico do Porto, Portugal.

${ }^{2} L A Q V$, REQUIMTE, Departamento de Química, Faculdade de Ciências e Tecnologia, Universidade Nova de Lisboa, Caparica, Portugal.

${ }^{3}$ Laboratório de Farmacologia e Biocompatibilidade Celular, Faculdade de Medicina Dentária, Universidade do Porto, Porto, Portugal.

${ }^{4}$ Centro de Investigação em Química-Linha 4, Faculdade de Ciências da Universidade do Porto, Departamento de Química e Bioquímica, Porto, Portugal.

\section{List of Tables}

Table 1 - Fitting parameters extracted from electrochemical impedance data using the Randles equivalent circuit.

A: Protein imprinted material without oriented charges (PIM) and B: Protein imprinted material with charged binding sites (C/PIM)

Table 2 - Selectivity study of the biosensors in the PBS, serum and urine artificial.

Table 3 - Determination of MSMB in serum and urine samples. 
Table 1 - Fitting parameters extracted from electrochemical impedance data using the Randles type equivalent circuit.

(A)

\begin{tabular}{cccccc}
\hline & Carbon & $\begin{array}{c}\text { Electropolymerization } \\
\text { PIM }\end{array}$ & $\begin{array}{c}\text { Electropolymerization } \\
\text { NIM }\end{array}$ & $\begin{array}{c}\text { After } \mathbf{H}_{2} \mathrm{SO}_{4} \\
\text { PIM }\end{array}$ & $\begin{array}{c}\text { After } \mathbf{H}_{2} \mathrm{SO}_{4} \\
\text { NIM }\end{array}$ \\
\hline $\mathbf{R}(\boldsymbol{\Omega})$ & 331.0 & 340.0 & 334.0 & 334.0 & 319.0 \\
$\mathbf{Q}$ & $7 \times 10^{-5}$ & $2 \times 10^{-5}$ & $4 \times 10^{-5}$ & $1 \times 10^{-5}$ & $6 \times 10^{-5}$ \\
$\mathbf{n}$ & 0.86 & 0.92 & 0.81 & 0.71 & 0.80 \\
$\mathbf{R}_{\mathbf{c t}}(\boldsymbol{\Omega})$ & 150.0 & 582.0 & 481.0 & 202.4 & 274.4 \\
$\mathbf{W}\left(\mathbf{\Omega s}^{-1 / 2}\right)$ & $6 \times 10^{-3}$ & $6 \times 10^{-3}$ & $6 \times 10^{-3}$ & $6 \times 10^{-3}$ & $6 \times 10^{-3}$ \\
\hline
\end{tabular}

(B)

\begin{tabular}{cccccc}
\hline Carbon & $\begin{array}{c}\text { Electropolymerization } \\
\text { C/PIM }\end{array}$ & $\begin{array}{c}\text { Electropolymerization } \\
\text { C/NIM }\end{array}$ & $\begin{array}{c}\text { After } \mathbf{H}_{2} \mathrm{SO}_{4} \\
\text { C/PIM }\end{array}$ & $\begin{array}{c}\text { After } \mathbf{H}_{2} \mathrm{SO}_{4} \\
\mathbf{C} / \mathbf{N I M}\end{array}$ \\
\hline $\mathbf{R}(\boldsymbol{\Omega})$ & 331.0 & 343.0 & 336.0 & 327.0 & 345.0 \\
$\mathbf{Q}$ & $7 \times 10^{-5}$ & $3 \times 10^{-5}$ & $2 \times 10^{-5}$ & $8 \times 10^{-5}$ & $9 \times 10^{-5}$ \\
$\mathbf{n}$ & 0.86 & 0.87 & 0.85 & 0.79 & 0.71 \\
$\mathbf{R}_{\mathbf{c t}}(\boldsymbol{\Omega})$ & 150.0 & 640.0 & 542.0 & 191.9 & 266.6 \\
$\mathbf{W}\left(\mathbf{\Omega s}^{-1 / 2}\right)$ & $6 \times 10^{-3}$ & $6 \times 10^{-3}$ & $6 \times 10^{-3}$ & $6 \times 10^{-3}$ & $6 \times 10^{-3}$ \\
\hline
\end{tabular}

Table 2 - Selectivity study of the biosensors in the PBS, serum and urine artificial.

\begin{tabular}{|c|c|c|c|c|c|c|}
\hline \multirow{2}{*}{ Characteristics } & \multicolumn{3}{|c|}{ PIM } & \multicolumn{3}{|c|}{ C/PIM } \\
\hline & PBS & Serum & Urine & PBS & Serum & Urine \\
\hline $\begin{array}{c}\text { Slope } \\
(\mu \mathrm{A} / \text { decade })\end{array}$ & -6.67 & -5.50 & -6.38 & -7.29 & -7.97 & -13.52 \\
\hline $\begin{array}{c}\text { LOD } \\
(\mathrm{ng} / \mathrm{mL})\end{array}$ & 0.090 & 0.10 & 0.18 & 0.12 & 0.084 & 0.079 \\
\hline $\mathbf{R}^{2}$ & 0.994 & 0.991 & 0.991 & 0.995 & 0.994 & 0.999 \\
\hline $\begin{array}{c}\text { Linear concentratio } \\
\text { range } \\
(\mathbf{n g} / \mathbf{m L})\end{array}$ & $0.1-200$ & $0.5-200$ & $0.5-200$ & $0.5-100$ & $0.5-100$ & $0.5-100$ \\
\hline
\end{tabular}


Table 3 - Determination of MSMB in serum and urine samples.

\begin{tabular}{cccccccc}
\hline Sample & $\begin{array}{c}\text { MSMB } \\
(\mathbf{n g} / \mathbf{m L})\end{array}$ & $\begin{array}{c}\text { Found } \\
(\mathbf{n g} / \mathbf{m L})\end{array}$ & $\begin{array}{c}\text { Recovery } \\
\mathbf{( \% )}\end{array}$ & $\begin{array}{c}\text { Relative } \\
\text { error } \\
\mathbf{( \% )}\end{array}$ & $\begin{array}{c}\text { Found } \\
(\mathbf{n g} / \mathbf{m L})\end{array}$ & $\begin{array}{c}\text { Recovery } \\
\mathbf{( \% )}\end{array}$ & $\begin{array}{c}\text { Relative } \\
\text { error } \\
(\%)\end{array}$ \\
\hline $\mathbf{1}$ & 0.2 & $0.17 \pm 0.05$ & $114.6 \pm 19.4$ & 12.8 & $0.22 \pm 0.05$ & $90.0 \pm 18.3$ & -11.1 \\
$\mathbf{2}$ & 1.0 & $1.1 \pm 0.11$ & $92.8 \pm 9.2$ & -7.8 & $1.1 \pm 0.13$ & $91.5 \pm 9.1$ & -9.2 \\
$\mathbf{3}$ & 3.0 & $2.9 \pm 0.10$ & $104.1 \pm 3.7$ & 4.0 & $2.9 \pm 0.19$ & $104.9 \pm 7.9$ & 4.7 \\
$\mathbf{4}$ & 20.0 & $19.4 \pm 0.89$ & $103.0 \pm 3.8$ & 3.0 & $20.6 \pm 1.1$ & $97.0 \pm 7.0$ & -3.1 \\
\hline
\end{tabular}


Protein Imprinted Materials designed with charged binding sites on screen-printed electrode for Microseminoorotein-Beta determination in biological samples.

Tânia S.C.R. Rebelo ${ }^{1,2,3}$, Carlos M. Pereira ${ }^{4 *}$, M. Goreti F. Sales ${ }^{1}$, João P. Noronha ${ }^{2}$ and Fernando Silva ${ }^{4}$

${ }^{1}$ BioMark-CINTESIS/ISEP, Instituto Superior de Engenharia do Instituto Politécnico do Porto, Portugal.

${ }^{2} L A Q V$, REQUIMTE, Departamento de Química, Faculdade de Ciências e Tecnologia, Universidade Nova de Lisboa, Caparica, Portugal.

${ }^{3}$ Laboratório de Farmacologia e Biocompatibilidade Celular, Faculdade de Medicina Dentária, Universidade do Porto, Porto, Portugal.

${ }^{4}$ Centro de Investigação em Química-Linha 4, Faculdade de Ciências da Universidade do Porto, Departamento de Química e Bioquímica, Porto, Portugal.

\section{Captions for Figures}

Figure 1 - Schematic representation of the synthetic process of PIM and C/PIM.

A: Carbon-SPE; B1: Electropolymerization of Caffeic acid with template; B2: Electropolymerization of Caffeic acid after the addition of dopamine to template; $\mathrm{C}$ : and binding site formation by template removal with $\mathrm{H}_{2} \mathrm{SO}_{4}$.

Figure 2 - EIS study over the subsequent modification steps of the carbon-SPE in $5.0 \mathrm{mM}$ $\left[\mathrm{Fe}(\mathrm{CN})_{6}\right]^{3-}$ and $5.0 \mathrm{mM}\left[\mathrm{Fe}(\mathrm{CN})_{6}\right]^{4-}$ PBS buffer.

A: Protein imprinted material without oriented charges (PIM) and B: Protein imprinted material with charged binding sites (C/PIM)

Figure 3 - Calibration curves of PIM, C/PIM, NIM and C/NIM based carbon-SPE biosensors obtained by SWV measurements in $5.0 \mathrm{mM}\left[\mathrm{Fe}(\mathrm{CN})_{6}\right]^{3-}$ and $5.0 \mathrm{mM}\left[\mathrm{Fe}(\mathrm{CN})_{6}\right]^{4-} \mathrm{PBS}$ buffer.

Figure 4 - Calibration curves displaying the effect of reused PIM and C/PIM carbon-SPE biosensors obtained by SWV measurements in $5.0 \mathrm{mM}\left[\mathrm{Fe}(\mathrm{CN})_{6}\right]^{3-}$ and $5.0 \mathrm{mM}\left[\mathrm{Fe}(\mathrm{CN})_{6}\right]^{4-}$ PBS buffer. 


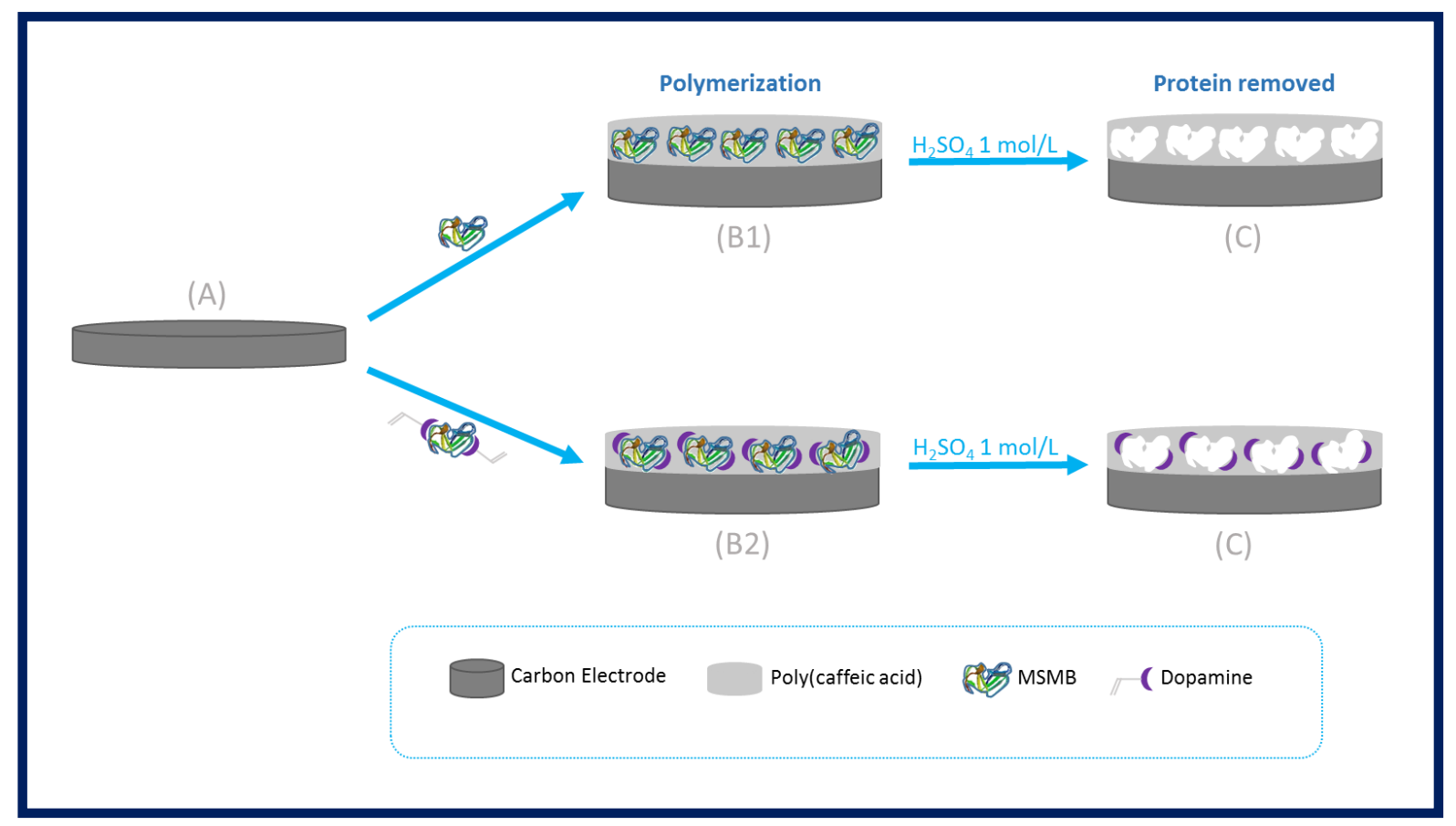

Figure 1 


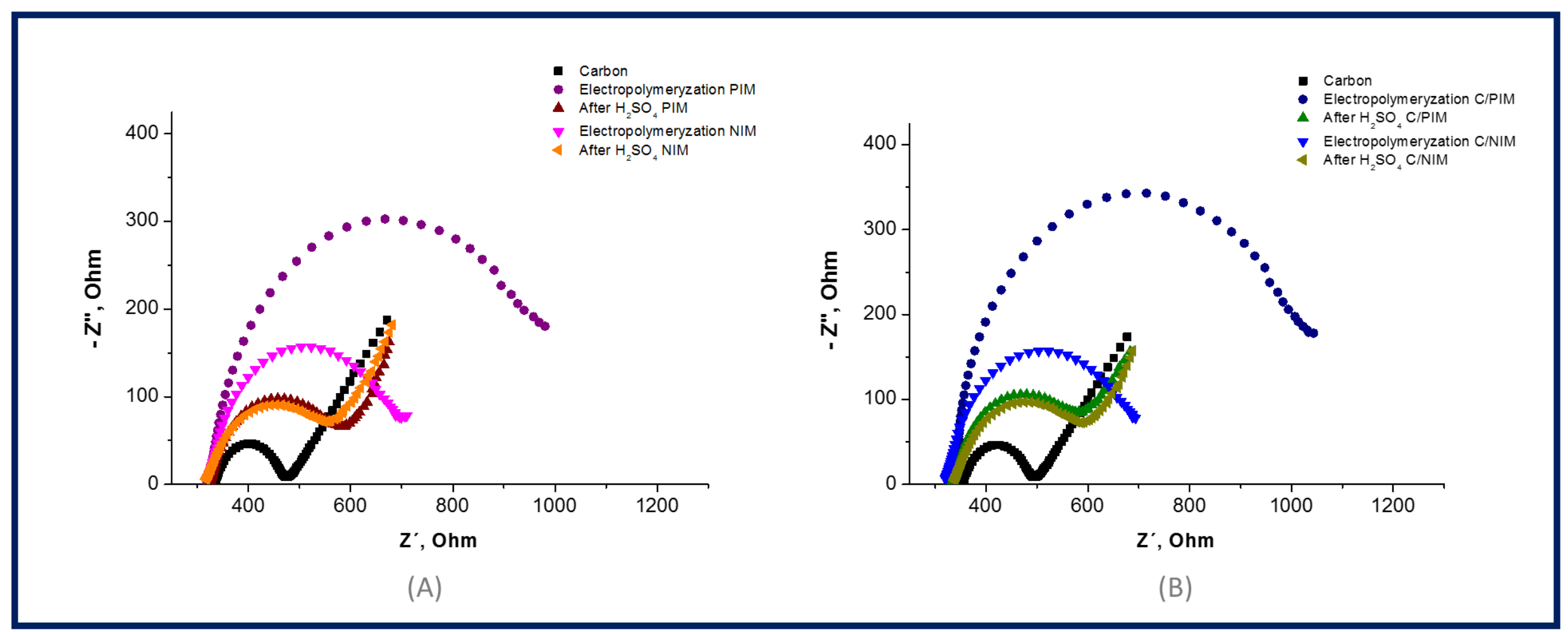

Figure 2 


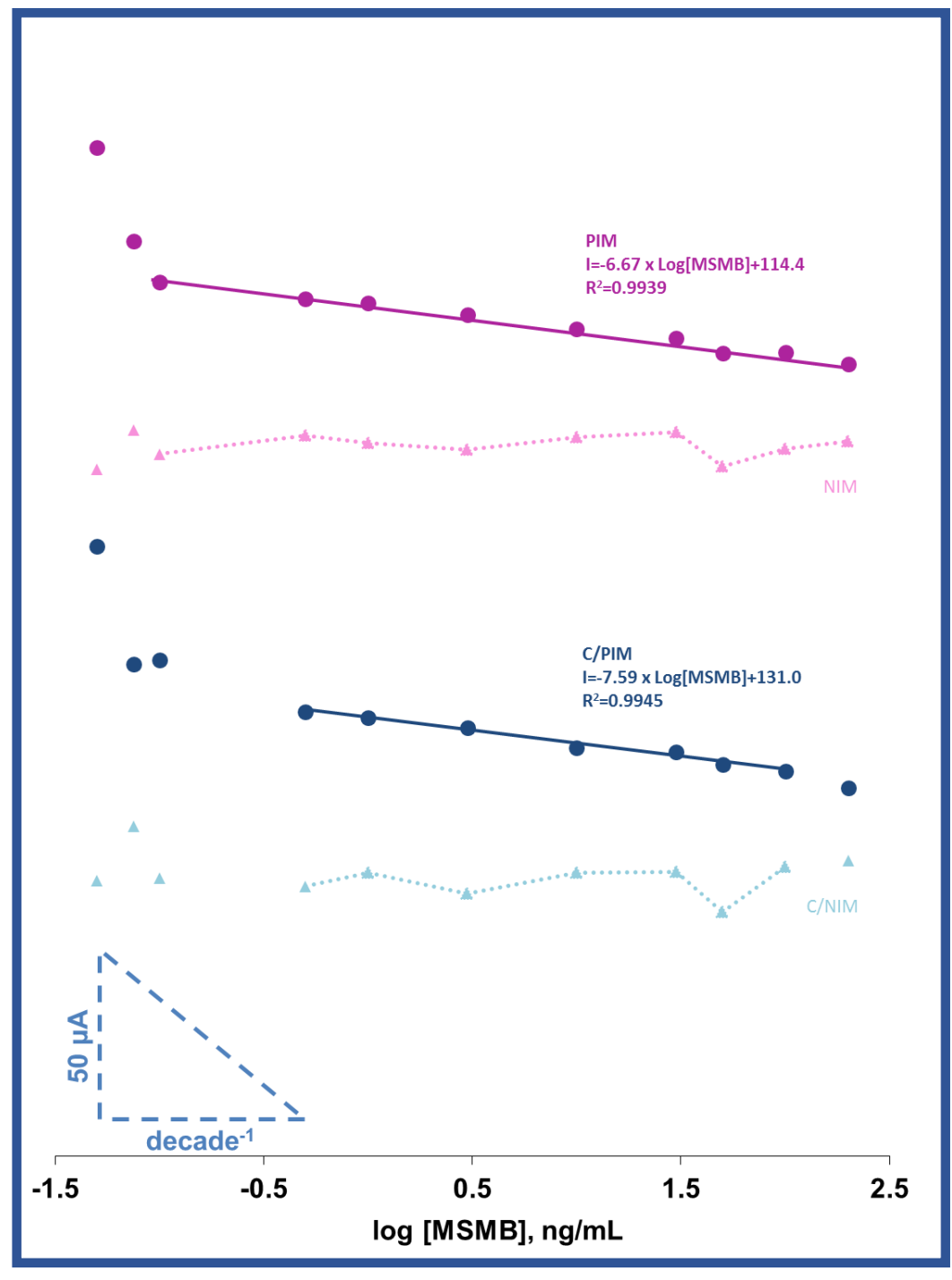

Figure 3 

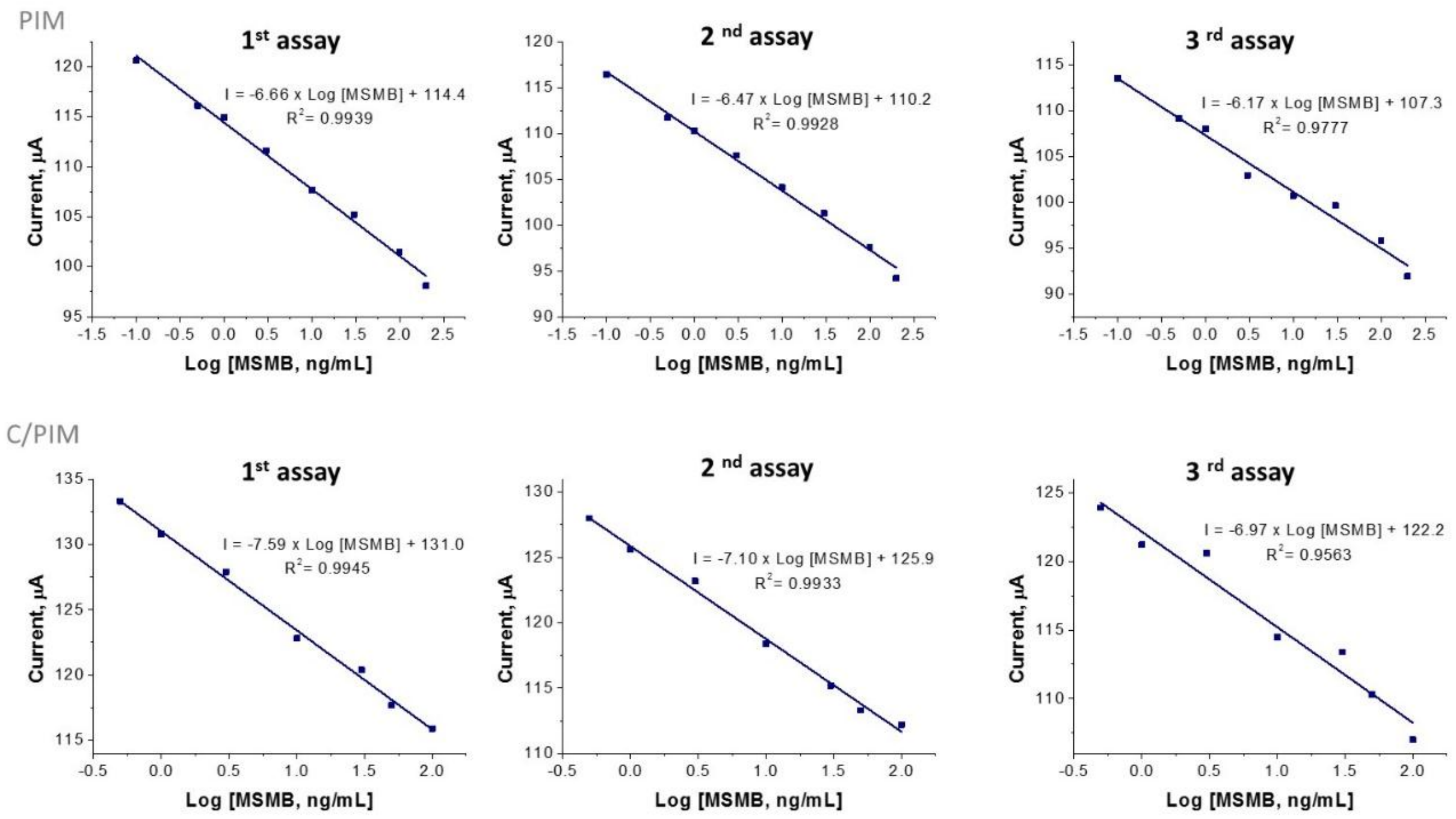

Figure 4 
Tania Rebelo is master in Chemical Engineering, currently doing PhD in Sustainable Chemistry in the Faculty of Science and Technology the New University of Lisbon, with the title "Improving the early diagnostic of prostate cancer by multiple biomarker detection with new biosensing devices". The research interests rely on the development of new sensing materials by molecularly-imprinting for a selective recognition of biomolecules acting as biomakers in health and their integration into sensory surfaces for electrical detection.

Carlos M. Pereira graduated in Chemistry from the University of Porto, Porto, Portugal, in 1986, and the Ph.D. degree in chemistry from the University of Porto, Porto, in 1997, dealing with sensing techniques based on Ion Transfer between two Immiscible Electrolyte Solutions. His main research interests are in the area of electrochemistry for chemical sensors and surface modification. He is an assistant professor at the Chemistry Department at the Faculty of Sciences University of Porto.

Goreti Sales received a degree in pharmaceutical sciences (1994) at the Faculty of Pharmacy of Porto University and a Ph.D. in analytical chemistry (2000) at the Porto University, Portugal, in 2000. She is a full professor in the Polytechnique Institute, School of Engineering since 2006. Her research interests are mainly devoted to research on biomimetic nanomaterials and biosensing devices. She initiated a new research unit named BioMark, Sensor Research in 2011 and in 2012 she has been awarded a Stating Grant by the European Research Council, targeting a new technical approach that merges biosensors with solar cells, devoted to the quick and low cost screening of cancer biomarkers.

João P. Noronha graduated with a degree in pharmaceutical sciences from the University of Porto, Porto, Portugal, in 1987, and the Ph.D. degree in organic chemistry from the New University of Lisbon, in 2001, dealing with chromatographic hyphenated techniques. His main research interests are in the chromatographic and mass spectrometric analysis of environmental, pharmaceutical, proteomic areas. He is a full professor at the Chemistry Department at the New University of Lisbon.

Fernando Silva graduated in chemical engineering from the University of Porto, Porto, Portugal, in 1972, and the Ph.D. degree in electrochemistry from Southampton University, UK, in 1980. His main research interests are in the field of surface electrochemistry covering different electrode materials (mercury, gold single crystal electrodes) and electrolytes (aqueous, organic and ionic liquids). He is a full professor of Chemistry at the Faculty of Sciences, University of Porto and dean of the Faculty of Sciences. 